\title{
Obtención de escopolamina en biorreactor a partir de cultivos de raíces de Brugmansia candida
}

\author{
Ángela María Otálvaro-Álvarez ${ }^{1, *}$, Mario Enrique Velásquez-Lozano ${ }^{2}$ \\ ${ }^{1}$ Facultad de Ingeniería, Universidad de La Salle, Bogotá, Colombia \\ ${ }^{2}$ Facultad de Ingeniería, Universidad Nacional de Colombia, Bogotá, Colombia
}

\begin{abstract}
Resumen
Teniendo en cuenta la importancia farmacológica de los alcaloides del tropano y la posibilidad de producirlos a partir de cultivos de tejidos de vegetales de especies como la Brugmansia candida, en este trabajo se evaluó la producción de uno de estos alcaloides a partir del cultivo de raíces adventicias en biorreactor. Para ello se desarrolló un sistema de reacción compuesto por dos unidades, una de crecimiento y otra de acondicionamiento del medio, y se evaluó la producción de biomasa y de este alcaloide luego de 21 días de cultivo, obteniendo como resultado 9,5 mg de escopolamina/g de raíces secas, resultado mayor al obtenido anteriormente en cultivos de raíces de este tipo en matraces de Erlenmeyer (6 mg/g de raíces secas), e incluso superior a lo reportado para cultivos de raíces transformadas de $B$. candida mediante biorreactor. Respecto a la biomasa, se obtuvo un índice de crecimiento de 1,58, similar al de 1,4 obtenido en matraces de Erlenmeyer, lo que sugiere que el cambio de escala no afectó de manera negativa la producción de biomasa.
\end{abstract}

Palabras clave: biorreactor, cultivos de raíces, alcaloides del tropano, escopolamina, Brugmansia candida.

Scopolamine production from Brugmansia candida roots culture using a bioreactor

\begin{abstract}
Given the pharmacological importance of tropane alkaloids and the possibilityof producing them from plant tissue cultures of plant species such as Brugmansia candida, the main goal of the present paper was to evaluate the alkaloid production of root cultures developed ina bioreactor. We set up a bioreaction system consisting of two units, one forbiomass growth and the other one for liquid medium conditioning. After 21 days of culture, biomass and scopolamine production were evaluated, resulting in the extraction of $9.5 \mathrm{mg}$ of scopolamine $/ \mathrm{g}$ of dry roots. This value was higher than the one obtained in a previous culture in Erlenmeyer flasks ( $6 \mathrm{mg} / \mathrm{g}$ of dry roots) and higher than the scopolamine extracted from hairy roots cultures using a bioreactor reported in other studies. Regarding biomass, the growth index (GI) was 1.58, similar to the GI obtained with cultures in Erlenmeyer flasks (GI 1.4), which suggests that scaling up the process did not affect biomass productionnegatively.
\end{abstract}

Key words: Bioreactor, roots culture, tropane alkaloids, scopolamine, Brugmansia candida.

\section{Introducción}

La Brugmansia candida es una especie conocida por su capacidad para producir un grupo de alcaloides entre los que se incluyen la escopolamina, la anisodamina y la hiosciamina, compuestos con una amplia gama de aplicaciones en medicina como agentes anticolinérgicos, antiespasmódicos, midriáticos y sedantes (Cardillo, A., Otálvaro, A., Busto, V., Talou, J., Velásquez, M., Giulietti, A., 2010).

En estudios anteriores se estableció que estos alcaloides se sintetizaban en las raíces de la planta y que luego viajaban a través de su xilema hasta las hojas (Wink, 1987). Esta es la razón por la cual, en la actualidad, la producción masiva de estos alcaloides se hace a través de la extracción de toneladas de hojas de cultivos de plantas que ya han alcanzado la madurez. En Australia, por ejemplo, se cultivan híbridos de $B$. candida para producir hojas jóvenes cuyo contenido de escopolamina es equivalente al $0,34 \%$ de su masa, y la producción promedio en un cultivo no fertilizado es de 4.360 $\mathrm{kg}$ de hojas secas por hectárea y por año, lo que se traduce en una producción de 14,8 $\mathrm{kg}$ de escopolamina por hectárea cultivada y por año (Griffin \& Lin, 2000). Sin embargo, debido a las características desfavorables de los cultivos

\footnotetext{
*Correspondencia:

Ángela María Otálvaro-Álvarez, amotalvaro@unisalle.edu.co

Recibido: 23 de julio de 2013

Aceptado: 27 de abril de 2014
} 
agronómicos, continuamente se buscan alternativas para su producción que resulten más ventajosas. Entre ellas, el cultivo in vitro de raíces se presenta como una buena opción (García, L. A., Perea., M., Reguero, M. T., 1993; Pitta-Álvarez, S. I., 1998; Niño, J., Gallego, C. M., Correa, Y. M., Mosquera, O. M., 2003; Mahagamasekera, M. G. P., Doran, P. M., 1998; Gontier, E., Clément, A., Tran, T. L. M., Gravot, A., Lièvre, K., Guckert, A., Bourgaud, F., 2002). Hasta ahora, estos cultivos se han desarrollado en bancos, y la producción de los compuestos por esta vía es todavía muy limitada. Piñeros, 2005, realizó estudios sobre la producción in vitro de escopolamina en cultivos de raíces de $B$. candida enmatraces de Erlenmeyer $(250 \mathrm{ml}), y$ logró producir un máximo de escopolamina de $6 \mathrm{mg} / \mathrm{g}$ de raíces secas.

En trabajos anteriores de cultivo de raíces de $B$. candida, se ha observado que en matraces de Erlenmeyer la producción de biomasa se incrementa cuando existe agitación, sin embargo, este mismo factor afecta negativamente la producción de alcaloides. Los valores reportados de la producción de escopolamina a los 20 días de cultivo son de 0,4 y 0,780 $\mathrm{mg} / \mathrm{g}$ de raíz húmeda en cultivos con agitación y sin esta, respectivamente (Pitta-Álvarez, S., 1998; Pitta-Álvarez, S., Giulietti, A.M., 2001).

Puesto que usado para este fin el cultivo in vitro de raíces convencional presenta algunas desventajas como la velocidad lenta de producción de biomasa, la necesidad de auxinas para promover el crecimiento de las raíces (que en algunos casos provoca ladisminución en el contenido de alcaloides), y la dificultad para mantener la estabilidad del cultivo y de la producción de metabolitos secundarios, se ha reconocido el potencial que representa el cultivo de raíces transformadas como herramienta para la obtención de productos vegetales sintetizados en la raíz (Flores, H. E., Filner, P. 1985; Hamill, J. D., Parr, A. J., Robins, R. J., Rhodes, M. J. C., 1986; Kamada, H., Okamura, N., Satake, M., Harada, H., Shimomura, K., 1986).

Sin embargo, en un estudio anterior llevado a cabo con raíces transformadas para la obtención de alcaloides del tropano en biorreactor, la producción de escopolamina fue menor a la obtenida en matraces de Erlenmeyer con raíces no transformadas que ya se mencionó ( $0,05 \mathrm{mg} / \mathrm{g}$ de raíces secas) (Cardillo, A., Otálvaro, A., Busto, V., Talou, J., Velásquez, M., Giulietti, A., 2010). Esto sugiere que, entre otros factores, el proceso de transformación puede afectar negativamente la producción de escopolamina en este caso particular.

Asimismo, trabajos como el de Carrizo, C., Pitta-Álvarez S., Kogan, M., Giulietti, A., Tomaro, M., (2001) han reportado que, además de los alcaloides esperados (escopolamina, hiosciamina y anisodamina), en estos cultivos de raíces transformadas de $B$. candida se detecta la presencia de otras sustancias como la cadaverina. Esta sustancia, que no se hace presente en la totalidad de los tejidos de la planta y se obtiene únicamente en respuesta a un factor de estrés, es una poliamina que también ha sido detectada en el género Datura.

De otro lado, cuando se busca llevar los procesos que han sido viables enmatraces de Erlenmeyer a una escala de producción mayor pasando al biorreactor, es necesario considerar que se presentan ciertas limitaciones, principalmente asociadas a problemas de transferencia de masa (oxígeno, nutrientes, etc.), y a la homogeneidad de las células del cultivo. Estos inconvenientes pueden conducir a la generación de estrés y, en algunos casos, a la lisis celular, ocasionando la pérdida del cultivo (Wyslouzil, B. E., Whipple, M., Chatterjee, C., Walcerz, D. B., Weathers, P. J., Hart, D. P., 1997. KinoOka, M., Hitaka, Y., Taya, M., Tone, S., 1999). Además, la producción de metabolitos en biorreactor está sujeta a ciertos factores, entre los que se encuentran la adición de reguladores del crecimiento, especialmente auxinas y citocianinas, que inducen la indiferenciación celular y promueven la proliferación in vitro; las variaciones en la concentración de nutrientes del medio, que dependen de los objetivos del cultivo; la adición de 'elicitores'; el estrés físico o químico que puede inducir la liberación de metabolitos; los factores físicos que incluyen la luz, la temperatura, el $\mathrm{pH}$ del medio, la aireación, la densidad celular y factores biológicos tales como las mutaciones y demás alteraciones genéticas inducidas que pueden modificar el cultivo y sus productos derivados. También se debe considerar la configuración del biorreactor, de modo que ésta sea la más adecuada para la producción del metabolito deseado, para lo cual se deben analizar los modelos reportados (de tipo airlift, de columna simple, de columna de burbujeo, de niebla, de tanque agitado, etc.), y las características del crecimiento del cultivo de acuerdo a sus necesidades particulares (Green \& Thomas, 1996;Chatterjee, et al., 1997; Jung, et al., 1998; Mahagamasekera \& Doran, 1998; Kino-Oka, et al., 1999; Hitaka, et al., 2000; Doran, 1997; Takahashi, et al., 2001; Weathers \& Kim, 2001; Zobayed \& Saxena, 2003; Huang, et al., 2004; Suresh, et al., 2004; Zobayed, et al., 2004; Suresh, et al., 2005, Luczkiewicz \& Kokotkiewicz, 2005, Martin \& Vermette, 2005, Savitha, et al., 2005, Guillon, et al., 2006).

Por esta razón, en este estudio se pretendió hacer un acercamiento al incremento de la producción de alcaloides del tropano, específicamente de escopolamina, en un biorreactor a partir de cultivos de raíces no transformadas de $B$. candida, con el objeto de establecer su potencial para crecer y producir el metabolito en tales condiciones.

\section{Materiales y métodos}

\section{Material vegetal}

Se emplearon semillas de $B$. candida recolectadas en el campus de la Universidad Nacional de Colombia. El árbol del que provenía el material está inventariado en 
el Herbario Nacional del Instituto de Ciencias Naturales de la Universidad Nacional de Colombia bajo el código 223783

\section{Obtención de raíces estériles normales de B. candida}

Esta etapa involucró varios procesos: la desinfección de los frutos y de los embriones de $B$. candida siguiendo el procedimiento descrito por Piñeros, 2005, y la siembra de los embriones en $15 \mathrm{ml}$ de medio B5 (Gamborg, et al., 1969) con suplemento de $20 \mathrm{~g} / \mathrm{l}$ de sacarosa, sin hormonas vegetales y con agar en una proporción de $10 \mathrm{~g} / 1$. Este procedimiento se llevó a cabo en frascos de $50 \mathrm{ml}$ con cubiertas de papel de aluminio. En cada frasco se plantaron entre dos y tres embriones. La incubación se hizoa temperatura ambiente y en condiciones de oscuridad.

A continuación se describe la operación del sistema de biorreacción en el cual se desarrolló el cultivo de las raíces por duplicado.

\section{Preparación de los inóculos de raíces normales de B. candida usados en el sistema de biorreacción}

Los inóculos usados en el sistema de biorreacción correspondían a las raíces estériles (de 1,5 a $2 \mathrm{~cm}$ ) obtenidas en los frascos con medio sólido en donde se cultivaron los embriones durante 30 días. Para preparar el inóculo, se hizo el corte de las raíces desde los embriones y la separación de los segmentos de tallo en la cámara de flujo laminar. El material se reunió en un recipiente estéril y se registró el peso fresco total que representaba la masa de inóculo.

\section{Adaptación del sistema de biorreacción para el cultivo de raíces normales de $B$. candida}

Se utilizó un sistema de dos unidades (reservorio y unidad de crecimiento) adaptado para el cultivo de las raíces normales de $B$. candida. En el reservorio se mantenía el medio de cultivo y se realizaba el registro de las condiciones de $\mathrm{pH}$, de temperatura y el oxígeno disuelto proveniente del medio. En un futuro, el uso de esta unidad permitirá implementar sistemas con reemplazo de medio para facilitar la extracción del producto o para controlar accidentes debidos a la contaminación. Se contó con un reactor Applikon ${ }^{\circledR}$ Z61101C006 de 3,2 1 de capacidad $(\mathrm{H} / \mathrm{D}=1,9)$ para el reservorio, el cual se acondicionó instalando en su interior un sistema de control de temperatura por medio de un intercambiador de calor, así como sensores de temperatura y de $\mathrm{pH}$, una sonda para la toma de muestras, un sistema de agitación (turbina Rushton) y una sonda para la salida constante de medio hacia la unidad de crecimiento. Cada cinco días se verificaba el contenido de azúcares, nitrógeno y alcaloides en el medio de cultivo y se retiraban $20 \mathrm{ml}$ de este. Para todos los ensayos, la unidad se cargó inicialmente con 2 $\mathrm{ml}$ de medio de cultivo previamente esterilizados.
El sistema de biorreacción completo contaba, además, con una unidad de crecimiento compuesta por un recipiente de vidrio de doble fondo que permitía la circulación de agua para mantener constante la temperatura en su interior y una malla de acero inoxidable que actuaba como soporte de las raíces. Esta malla tenía una amplitud de poro de $1 \mathrm{~mm}$ y se ubicó a $5 \mathrm{~cm}$ de la tapa y a $18 \mathrm{~cm}$ del fondo de la unidad de crecimiento, con el fin de dar espacio al desarrollo completo de las raíces, las cuales alcanzan una elongación máxima de $20 \mathrm{~cm}$ durante el periodo de cultivo según lo reportado por Piñeros, 2005.

En la unidad de crecimiento se colocó una boquilla para el suministro del medio. La distancia entre la malla y la tapa, así como el diseño de la boquilla, garantizaron que la aspersión fuera homogénea sobre toda el área de la malla y cubriera completamente la masa de raíces. Además de la boquilla para la entrada del medio, la tapa de esta unidad tenía dos puertos, uno donde se instaló una sonda para la salida del medio desde la unidad de crecimiento hacia el reservorio, y otro acondicionado con un filtro de $0,22 \mu \mathrm{m}$ para la salida del aire que ingresaba a la unidad.

El aire empleado para el crecimiento provenía de un aireador y era conducido a través de mangueras de silicona a una unidad de humidificación antes de su ingreso al proceso;el flujo de aire empleado fue de $0,47 \mathrm{l} / \mathrm{min}$ (correspondientes a $0,24 \mathrm{vvm}$ ). La unidad de crecimiento se cubrió para oscurecer su interior, ya que cuando los cultivos se desarrollaban en presencia de la luz, el crecimiento de las raíces se daba de forma paralela al desarrollo de segmentos de tallo.

\section{Operación del sistema de biorreacción para el crecimiento de raíces no transformadas de B. candida}

Después de inocular la unidad de crecimiento colocando las raíces $(3,0 \mathrm{~g}$ de raíces frescas/l) sobre la malla de acero inoxidable, se añadieron $0,5 \mathrm{~g} / 1 \mathrm{de}$ ampicilina $\mathrm{y}$ $0,5 \mathrm{ml} / \mathrm{lde}$ nistatina $(100.000 \mathrm{UI} / \mathrm{ml})$ al medio de cultivo que se encontraba en el reservorio para controlar posibles contaminaciones. En cuanto a las condiciones del ensayo, luego de añadir el antibiótico y el antimicótico, el pH del medio de cultivo fue de 7,0. Para evitar la deshidratación y la pérdida de viabilidad de las raíces, el flujo de aire y de medio debía iniciarse rápidamente. El flujo de medio que entraba a la unidad de crecimiento se mantuvo en $0,30 \mathrm{ml} / \mathrm{s}$, mientras que el flujo de medio que salía de la unidad se estabilizó en $0,39 \mathrm{ml} / \mathrm{s}$; estos flujos se ajustaron para evitar que el medio se acumulara en la unidad de crecimiento y así garantizar su continuo movimiento entre las dos unidades. Además, la operación en el sistema de biorreacción se desarrolló de modo que el aire se mezclara con el medio de cultivo en la boquilla de ingreso a la unidad de crecimiento, generando burbujas muy finas de medio que facilitaban su aspersión uniforme sobre las raíces. 


\section{Seguimiento del cultivo de las raíces no transformadas de B. candida en el reactor}

Las condiciones en la unidad de reservorio, es decir el $\mathrm{pH}$ y la temperatura del medio, se registraban a diario. Cada cinco días se tomaba una muestra del medio de cultivo para determinar la concentración de alcaloides y azúcares.

\section{Procedimiento de 'elicitación' de las raíces no transformadas de B. candida en el sistema de biorreacción}

De acuerdo con los desarrollos obtenidos por Piñeros, 2005, quien estableció las ventajas del uso de sulfato de cobre como elicitor, se aplicó esta sustancia al medio de cultivo en la dosis indicada $(0,2 \mathrm{mM})$ en el día 21 del cultivo, manteniendo las mismas condiciones del periodo de crecimiento. El elicitor se dejó actuar durante 24 horas, al cabo de las cuales se daba por terminado el ensayo. En este momento se detenían las bombas y el suministro de aire y se procedía a abrir ambas unidades, se recogía una última muestra del medio líquido y se recolectaban las raíces.

\section{Determinaciones analíticas}

Determinación de peso fresco. El peso fresco de las raíces (PF) se determinó luego de filtrar el medio de cultivo, lavar las raíces con abundante agua y secarlas de forma rápida con papel absorbente.

Determinación del peso seco. El peso seco de las raíces (PS) se determinó luego de secarlas en una estufa a $80^{\circ} \mathrm{C}$ hasta obtener un peso constante (Perry, 1981).

Determinación de la humedad. La humedad se determinó usando la información del peso fresco (PF) y el peso seco (PS).

\section{Extracción del alcaloide}

Para cuantificar la escopolamina presente tanto en las raíces como en el medio de cultivo, se hizo necesaria su extracción aplicando los protocolos empleados por Piñeros, 2005. Para las raíces, el proceso consistió en la extracción sólido-líquido de $0,5 \mathrm{~g}$ de raíces con $40 \mathrm{ml}$ de una solución compuesta por cloroformo, metanol y amoniaco (15:5:1) a temperatura ambiente en un agitador orbital a 100 r.p.m durante 72 horas. A continuación se mezclaba la solución resultante con $50 \mathrm{ml}$ de agua y $25 \mathrm{ml}$ de cloroformo en un embudo de decantación del que se recuperaba la fase orgánica, lacual se sometía a evaporación con aire y resuspensión en la fase móvil para la cuantificación del alcaloide. Dicha cuantificación se realizó por cromatografía líquida de alta eficacia (CLAE) con el método descrito por Piñeros, 2005. La escopolamina se identificó tomando como base el tiempo de retención del estándar (-) escopolamina $\mathrm{HBr}$ trihidratada (Sigma Aldrich) y se cuantificó por medio de una curva de calibración. Para este ensayo se contó con un equipo Waters ${ }^{\circledR}$ (Milford, MA, Estados Unidos) que contaba con un detector de absorbancia UV 486 programado a $210 \mathrm{~nm}$. El software para el análisis de los datos usado fue el Millenium 2000 de Waters (Milford, MA, Estados Unidos). Para el análisis del alcaloide se usó como fase móvil una mezcla que contenía $10 \%$ en volumen de acetonitrilo, $89 \%$ de una solución de $50 \mathrm{mM}$ de $\mathrm{KH}_{2} \mathrm{PO}_{4}$ y $1 \%$ de trietanolamina, y se trabajó con cromatografía isocrática. El pH de la fase móvil se ajustó en 3,5 empleando ácido fosfórico y flujo de $1 \mathrm{ml} /$ minuto. La columna empleada para la separación fue una $\mathrm{C} 18$ en fase reversa (Chromolith performance RP-18e de $100 \mathrm{~mm}$ de longitud y 4,6 $\mathrm{mm}$ de diámetro interno, Merck KGA 64271, Darmstadt, Alemania). Todas las pruebas se desarrollaron a temperatura ambiente y se estableció un tiempo de análisis de 15 minutos para cada una; la inyección en el equipo fue manual y su volumen fue de $20 \mathrm{ml}$. Las muestras inyectadas correspondieron a los extractos obtenidos disueltos de nuevo en la fase móvil.El tiempo de retención para la escopolamina se determinó en $4,8 \pm 0,5$ minutos.

\section{Determinación de azúcares por cromatografía líquida de alta eficacia}

La determinación se hizo cuantificando la cantidad de sacarosa, de glucosa y de fructosa presente en el medio de cultivo durante el tiempo de cultivo. Los azúcares se identificaron con base en los tiempos de retención de los estándares de sacarosa, glucosa y fructosa (Sigma Aldrich) y la cuantificación se llevó a cabo por medio de una curva de calibración. Para la realización de este ensayo se contó con un equipo Waters ${ }^{\circledR}$ (Milford, MA, Estados Unidos) equipado con un detector de índice de refracción IR 410. Los datos se analizaron con el software Millenium 2000 de Waters ${ }^{\circledR}$ (Milford, MA, Estados Unidos). Para este análisis se usó como fase móvil agua desionizada a un flujo volumétrico de $0,5 \mathrm{ml} / \mathrm{min}$. La columna empleada para la separación fue una Sugar-Pak ${ }^{\mathrm{TM}}$ de $300 \mathrm{~mm}$ de longitud y $6,5 \mathrm{~mm}$ de diámetro. Todos los análisis se desarrollaron a una temperatura de $84^{\circ} \mathrm{C}$. El tiempo de cada análisis se estableció en 15 minutos. Los tiempos aproximados de retención para los tres azúcares evaluados fueron los siguientes: sacarosa, $7,49 \pm 0,2$ minutos, glucosa, 9,46 $\pm 0,09$ minutos y fructosa, $11,8 \pm 0,04$ minutos.

\section{Determinación por espectrofotometría del nitrógeno presente en el medio de cultivo}

Esta determinación se realizó solamente en uno de los ensayos y buscaba caracterizar el consumo de nutrientes, específicamente de las fuentes de nitrógeno, a lo largo del tiempo de crecimiento de las raíces. Se usó un espectrofotómetro NANOCOLOR ${ }^{\circledR} 500$ D (Macherey Nagel) a $365 \mathrm{~nm}$ después de que las muestras se pusieran en contacto con 2,6-dimetil fenol mezclado con ácido sulfúrico/ácido fosfórico, según lo descrito para la determinación de nitratos en el Test 1- 65 del catálogo del equipo empleado. 


\section{Resultados y discusión \\ Operación del biorreactor}

En cuanto a la configuración de las dos unidades empleadas para el cultivo, se presentaron inconvenientes a la hora de evacuar el aire suministrado en la unidad de crecimiento, yaque esta contaba únicamente con una salida, la cual se vio afectada por la caída de la presión a través de un filtro de $0,20 \mu \mathrm{m}$, lo que ocasionó problemas por el incremento de la presión en el sistema. Para superar estos inconvenientes fue necesario cambiar el filtro por lo menos una vez durante el cultivo para evitar que se taponara, e instalar otras salidas en el biorreactor para facilitar la evacuación del aire de exceso. En el laboratorio se usaron mangueras de silicona para el transporte del medio entre las dos unidades. La fragilidad de dichas mangueras, y el continuo desgaste al que se ven sometidas por la acción de las bombas peristálticas, hace pensar que se deben considerar otro tipo de ductos para el transporte del medio entre las unidades si se quiere llegar a una escala superior de producción.

Es importante destacar que cuando se añadió el sulfato de cobre durante el último día del ensayo, el pH disminuyó de manera considerable.

En cuanto a los resultados relativos al cambio en la concentración de azúcares en el medio a lo largo del cultivo, se evidenció que el mayor consumo de azúcares se presentó durante los 12 primeros días, al cabo de los cuales esta variable tendió a estabilizarse, pasando de los $20 \mathrm{~g} / \mathrm{l}$ iniciales a una concentración de azúcares aproximada de 12 g/l; durante este tiempo se observó un consumo aproximado del $40 \%$, lo que coincide con los consumos presentados por Piñeros, 2005, para cultivos de raíces no transformadas de $B$. candida en matraces de Erlenmeyer y con los resultados de Cardillo, A., Otálvaro, A., Busto, V., Talou, J., Velásquez, M., Giulietti, A., 2010 para cultivos de raíces transformadas de esta misma especie en biorreactor.

Respecto al crecimiento de las raíces, se contó con un inóculo de 5,95 $\pm 0,07 \mathrm{~g}$ y a los 21 días de cultivo se llegó a una masa final de 15,36 $\pm 1,33 \mathrm{~g}$ (Figura 1).Estos pesos corresponden a raíces frescas. La humedad de las raíces fue de $92,5 \pm 0,7 \%$. Con esta información se determinó el índice de crecimiento de las raíces de acuerdo con la ecuación.

$$
\begin{gathered}
I C=\frac{(15,36-5,95)}{5,95} \\
I C=1,58
\end{gathered}
$$

En este caso, el índice de crecimiento fue de 1,58, que es un valor mayor al obtenido en las raíces evaluadas en la curva de crecimiento cuando el cultivo se hizo en matraces de Erlenmeyer de $125 \mathrm{ml}$, en las cuales se alcanzó un índice de crecimiento de 1,4 (Otálvaro, 2009).
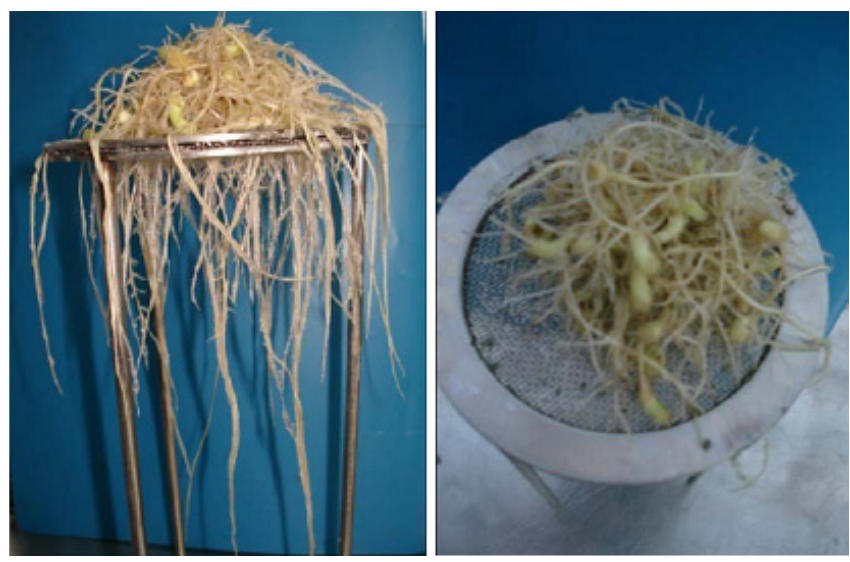

Figura 1. Raíces adventicias cultivadas en el biorreactor luego de 21 días de crecimiento

Carrillo, et al., 2010, encontraron que en un cultivo de raíces transformadas de $B$. candida desarrollado en un sistema de biorracción por inmersión con mallas de soporte, el índice de crecimiento fue de 3,93, valor muy superior al reportado en este trabajo, lo que ratifica que la transformación de las raíces fomenta su crecimiento (Veena \& Taylor, 2007).

\section{Análisis cuantitativo de escopolamina por cromatografía líquida de alta eficacia}

Se analizaron las muestras del medio de cultivo tomadas en los días 4, 8, 12, 16, 20 y 21 para determinar el contenido de escopolamina. En ninguna de las muestras se observó la presencia del metabolito en cantidades detectables (nivel de detección mínimo: 0,01 mg de escopolamina/ml). Estos resultados indican que no hubo liberación del alcaloide al medio de cultivo o que, si la hubo, se encontraba por debajo de los límites de detección del método empleado. Con estos resultados se confirmó el hecho presentado por otros investigadores en el sentido de que la presencia del metabolito en el mediono se evidencia en cultivos que no han sido expuestos a un agente elicitor (Piñeros, 2005; Liu, et al., 2003).

La aplicación de $0,2 \mathrm{~mm}$ de sulfato de cobre con el propósito inicial de favorecer la liberación del metabolito al medio bajo las condiciones experimentales probadas, no arrojó un resultado positivo. Esta situación pudo deberse a que el contacto entre el elicitor y la masa de raíces generado por la aspersión no fue suficiente, como sí lo fue para las unidades experimentales de menor volumen y cultivos sumergidos, donde la probabilidad de interacción entre la biomasa y el compuesto elicitor es mucho mayor y donde el estrés mecánico también actúa como precursor de la liberación del metabolito al medio de cultivo (Dörnenburg, H., Knorr, D., 1995). 
En cuanto a la escopolamina extraída de las raíces, se determinó un valor de 9,5 $\pm 3,04 \mathrm{mg} / \mathrm{g}$ de raíces secas, equivalente a $0,73 \pm 0,23 \mathrm{mg} / \mathrm{g}$ de raíces húmedas; dicho resultado es mayor que el valor promedio encontrado por Piñeros, 2005, de6 mg/g de raíces secas reportado para cultivos en matraces de Erlenmeyer. Sin embargo, el valor fue menor al máximo reportado por Grajales, 2008, al evaluar tres tratamientos en los cuales se aplicaba L-arginina en concentraciones de 10,100 y $1.000 \mathrm{mg} /$ lcomo precursora de la escopolamina en el medio de cultivo de Schenk y Hilderandt, obteniéndose un rendimiento de 10,134 mg/g con el tratamiento 3 (1.000 mg/L de L-arginina) en el día 15 del cultivo.

De otro lado, en el trabajo de Cardillo, et al., 2010, sobre el cultivo de raíces transformadas en biorreactor, los autores reportan una producción del metabolito de $0,05 \pm 0,01 \mathrm{mg} / \mathrm{g}$ de raíces secas. Como se observa, este valor es inferior al obtenido en este trabajo empleando raíces no transformadas, lo que permite evidenciar que la producción del metabolito de interés en biorreactor puede haberse visto afectada, entre otros factores, por el proceso de transformación de las raíces (Bonhomme, et al., 2000; Bulgakov, V. P, et al., 2002; Bulgakov, V. P, et al., 2004; Bulgakov, V. P., 2008).

Por otra parte, en el trabajo desarrollado por Otálvaro, 2009, con raíces transformadas de B. candida clon Arg3 (descrito en Cardillo, et al., 2010) y en el mismo sistema de biorreación de dos unidades empleado en este trabajo, se encontró un índice de crecimiento de 1 y una producción de escopolamina de $0,07 \mathrm{mg} / \mathrm{g}$ de raíces frescas. Se observa de nuevo aquí una baja producción del alcaloide utilizando el clon transformado (Ramírez \& Suárez, 1993; Cardillo, et al., 2010).

\section{Conclusiones}

Es posible producir escopolamina en biorreactor a partir de cultivos de raíces no transformadas de $B$. candida con rendimientos en cuanto a índice de crecimiento $\mathrm{y}$ concentración de alcaloide similares a los obtenidos en cultivos desarrollados en matraces de Erlenemeyer, lo que evidencia la capacidad de escalar la producción.

Además, al comparar los resultados obtenidos con otros reportados para cultivos de raíces transformadas de la misma especie, se observó que, aunque el proceso de transformación de dichas raíces promueve la generación de biomasa, puede estar afectando de manera negativa la síntesis de escopolamina en las raíces.

Se evidenció, asimismo, que en biorreactor y bajo las condiciones evaluadas en este trabajo, la elicitación con sulfato de cobre no producía el efecto esperado en cuanto a la liberación de escopolamina al medio de cultivo. Para futuros estudios se recomienda probar otros elicitores, como la L-arginina, que han demostrado tener un efecto positivo como precursores de la escopolamina en cultivos de raíces no transformadas.

\section{Conflicto de interés}

Los autores declaran que no tienen ningún conflicto de interés.

\section{Bibliografía}

Bulgakov, V. P. 2008. Functions of rol genes in plant secondary metabolism. Biotechnology Advances 26: 318-324.

Bulgakov, V. P., Tchernoded, G. K., Mischenko, N. P., Khodakovskaya, M. V., Glazunov, V. P., Radchenko, S. V., Zvereva, E. V., Fedoreyev, S. A., Zhuravlev, Y. N. 2002. Effect of salicylic acid, methyl jasmonate, ethephon and cantharidin on anthraquinone production by Rubiacordifolia callus cultures transformed with the rolB and rolC genes. Journal of Biotechnology 97: 213-221.

Bulgakov, V.P., Tchernoded, G. K., Mischenko, N. P., Shkryl, Y.N., Fedoreyev, S. A., Zhuravlev, Y. N. 2004. The rolB and rolC genes activate synthesis of anthraquinones in Rubiacordifolia cells by mechanism independent ofoctadecanoid signaling pathway. Plant Science 166: 1069-1075.

Bonhomme, V., Laurain-Mattar, D., Lacoux, J., Fliniaux, M. A., Jacquin-Dubreuil, A. 2000. Tropane alkaloid production by hairy roots of Atropa belladonna obtained after transformation with Agrobacterium rhizogenes 15834 and Agrobacterium tumefaciens containing rolA, B, C genes only. Journal of Biotechnology 81: 151-158.

Cardillo, A.B.; Otálvaro, A.M.; Busto, V.D.; Talou, J.R.; Velasquez, L.M.E.; Giulietti, A.M. 2010. Brugmansia candida hairy root cultures in bioreactors as an anisodamine production system. Process Biochemistry 45 (9): 1577-1581.

Chatterjee, C., Correll, M. J., Weathers, P. J., Wyslouzil, B. E., Walcerz, D. B. 1997. Simplified acoustic window mist bioreactor. Biotechnology Techniques 11: 155-158.

Doran, P. M. 1997. Hairy roots: Culture and applications, CRC Press. Ámsterdam

Dörnenburg, H., Knorr, D. 1995. Strategies for the improvement of secondary metabolite production in plant cell cultures. Enzyme and Microbiology Technology 17(8):674-684.

Flores, H. E., Filner, P. 1985. Metabolic relationships of putrescine, GABA and alkaloids in cell and root cultures of Solanaceae. En: Newman, K. H., Barz, W.,Reinhard, E. eds, Primary and secondary metabolism of plant cell cultures. SpringerVerlag, New York, p. 174-185.

García, L. A., Perea., M., Reguero, M. T. 1993. Brugmansia: una especie promisoriapara la producción de alcaloides del tropano. Revista Colombiana de Ciencias QuímicoFarmaceúticas 21: 5.

Gontier, E., Clément, A., Tran, T. L. M., Gravot, A., Lièvre, K., Guckert, A., Bourgaud, F. 2002. Hydroponic combined 
with natural or forced root permeabilization: A promising technique for plant secondary metabolite production. Plant Science (Limerick), 163: 723-732.

Grajales, E. 2008. Elicitación de raíces normales cultivadas in vitro de Brugmansia Candida (Solanaceae) con precursores de alcaloides del tropano. Tesis. Facultad de Tecnologías, Universidad Tecnológica de Pereira, Pereira.

Green, K. D., Thomas, N. H. 1996. An integrated "Root tube" bioreactor/separator for transformed root cultures. Journal of Fermentation and Bioengineering 81: 453-457.

Griffin, W. J., Lin, G. D. 2000. Chemotaxonomy and geographical distribution of tropane alkaloids.Phytochemistry 53: 623-637.

Guillon, S., Trémouillaux-Guiller, J., Pati, P. K., Rideau, M., Gantet, P. 2006. Hairy root research: Recent scenario and exciting prospects.Current Opinion in Plant Biology 9: $341-346$

Hamill, J. D., Parr, A. J., Robins, R. J., Rhodes, M. J. C. 1986. Secondary product formation by cultures of Beta vulgaris and Nicotianarustica transformed with Agrobacterium rhizogenes. Plant Cell Reports 5: 111-114.

Hitaka, Y., Takahashi, Y., Kino-oka, M., Taya, M., Tone, S. 2000. Culture of red beet hairy roots by considering variation in sensitivity of tip meristems to hydraulic stress. Biochemical Engineering Journal 6: 1-6.

Huang, S. Y., Hung, C. H., Chou, S. N. 2004. Innovative strategies for operation of mist trickling reactors for enhanced hairy root proliferation and secondary metabolite productivity. Enzyme and Microbial Technology 35: 22-32.

Jung, K. H., Kwak, S. S., Liu, J. R. 1998. Procedure for biomass estimation considering the change in biomass volume during high-density culture of hairy roots.Journal of Fermentation and Bioengineering 85: 454-457.

Kamada, H., Okamura, N., Satake, M., Harada, H., Shimomura, K. 1986. Alkaloid production by hairy root cultures in Atropa belladonna. Plant Cell Reports 5: 239-242.

Kino-Oka, M., Hitaka, Y., Taya, M., Tone, S. 1999. High-density culture of red beet hairy roots by considering medium flow condition in a bioreactor. Chemical Engineering Science 54, 3179-3186.

Liu, C. Z., Guo, C., Wang, Y. C., Ouyang, F. 2003. Comparison of various bioreactors on growth and artemisinin biosynthesis of Artemisia annua L. shoot cultures. Process Biochemistry 39: $45-49$

Luczkiewicz, M., Kokotkiewicz, A. 2005. Co-cultures of shoots and hairy roots of Genistatinctoria L. for synthesis and biotransformation of large amounts of phytoestrogens.Plant Science 169: 862-871.

Mahagamasekera, M. G. P., Doran, P. M. 1998. Intergeneric coculture of genetically transformed organs for the production of scopolamine. Phytochemistry 47: 17-25.

Martin, Y., Vermette, P. 2005. Bioreactors for tissue mass culture: Design, characterization, and recent advances. Biomaterials 26: 7481-7503.
Niño, J., Gallego, C. M., Correa, Y. M., Mósquera, O. M. 2003. Production of scopolamine by normal root cultures of Brugmansia candida. Plant Cell, Tissue and Organ Culture 74: 289-291.

Otálvaro A. 2009. Evaluación de un sistema de biorreacción para la producción de escopolamina por cultivo de raíces de Brugmansia candida. Tesis de Doctorado. Departamento de Ingeniería Química y Ambiental, Universidad Nacional de Colombia, Bogotá.

Perry, D.A. 1981. Handbook of vigour test methods. International Seed Testing Association. Zurich, Switzerland. p. 72

Piñeros, Y. 2005. Producción de escopolamina e hiosciamina mediante cultivo in vitro de raíces de Brugmansia candida. Tesis de Maestría. Departamento de Ingeniería Química y Ambiental, Universidad Nacional de Colombia, Bogotá.

Pitta-Álvarez, S.I. 1998. Producción in vitro de alcaloides del tropano empleando raíces transformadas de Brugmansia candida. Tesis. Departamento de Microbiología, Inmunología y Biotecnología, Universidad de Buenos Aires, Buenos Aires, p. 214

Pitta-Álvarez, S. I., Giulietti, A. M. 2001. Hairy roots of Brugmansia candida that grow without agitation: Biotechnological implications, Biotechnology progress 17(4): 661-664.

Ramírez, Y., Suárez, W. 1993. Contribución al estudio del género Brugmansia mediante el cultivo de tejidos vegetales in vitro II. Tesis. Facultad de Ciencias, Departamento de Farmacia, Universidad Nacional de Colombia, Bogotá.

Savitha, B. C., Thimmaraju, R., Bhagyalakshmi, N., Ravishankar, G. A. 2006. Different biotic and abiotic elicitors influence betalain production in hairy root cultures of Beta vulgaris in shake-flask and bioreactor. Process Biochemistry 41: 50-60.

Suresh, B., Thimmaraju, R., Bhagyalakshmi, N., Ravishankar, G. A. 2004. Polyamine and methyl jasmonate-influenced enhancement of betalain production in hairy root cultures of Beta vulgaris grown in a bubble column reactor and studies on efflux of pigments. Process Biochemistry 39: 2091-2096.

Suresh, B., Bais, H. P., Raghavarao, K., Ravishankar, G. A., Ghildyal, N. P. 2005 Comparative evaluation of bioreactor design using Tagetespatula L. hairy roots as a model system. Process Biochemistry 40: 1509-1515.

Takahashi, Y., Hitaka, Y., Kino-oka, M., Taya, M., Tone, S. 2001 Evaluation of growth property of red beet hairy roots depending on condition of inocula and its application to culture control with fuzzy logic theory.Biochemical Engineering Journal 8: 121-127.

Veena, V., Taylor, C. G. 2007.Agrobacterium rhizogenes: Recent developments and promising applications.In Vitro Cellular \& Developmental Biology-Plant 43: 383-403.

Weathers, P. J., Kim, Y. J. 2001. Transformed roots of Artemisia annua exhibit an unusual pattern of border cell release. In Vitro Cellular \& Developmental Biology-Plant 37: 440-445. 
Wink, M. 1987. Physiology of the accumulation of secondary metabolites with special reference to alkaloids. En: Constabel, F., Vasil, I. eds. Cell culture and somatic cell genetics of plants. Vol 4: Cell culture in Phytochemistry, Academic press, p. 17-41.

Wyslouzil, B. E., Whipple, M., Chatterjee, C., Walcerz, D. B., Weathers, P. J., Hart, D. P. 1997. Mist deposition onto hairy root cultures: Aerosol modeling and experiments. Biotechnology Progress 13: 185-194.
Zobayed, S. M. A., Saxena, P. K. 2003. In vitro-grown roots: A superior explant for prolific shoot regeneration of St. John's wort (Hypericumperforatum L. cv 'New Stem') in a temporary immersion bioreactor, Plant Science 165: 463-470.

Zobayed, S., Saxena, P. K. 2004. Production of St. John's wort plants under controlled environment for maximizing biomass and secondary metabolites. In Vitro Cellular \& Developmental Biology-Plant 40: 108-114. 